\title{
SDU
}

\section{Video games as cultural participation: understanding games playing in England using the Taking Part survey}

\author{
by
}

Karol J. Borowiecki and Hasan Bakhshi

Discussion Papers on Business and Economics

No. $5 / 2017$

FURTHER INFORMATION

Department of Business and Economics Faculty of Business and Social Sciences University of Southern Denmark Campusvej 55, DK-5230 Odense M

Denmark 


\title{
Video games as cultural participation: understanding games playing in England using the Taking Part survey
}

\author{
Karol J. Borowiecki* and Hasan Bakhshi ** \\ *Department of Business and Economics, University of Southern Denmark \\ ** Nesta
}

March 2017

\begin{abstract}
$\underline{\text { ABSTRACT }}$
This study addresses the important and recurring question of whether playing video games is detrimental to the socio-economic development of a person. It does this by using novel data from the Taking Part Survey in England to establish whether games playing is associated with particular socio-economic characteristics and/or other forms of cultural participation. The results do not indicate any obviously negative effects of video games playing: those who play are typically better educated and wealthier, and games players are also more likely than non-games players to participate in other forms of culture, especially through active participation. These findings are reinforced when comparing the characteristics of individuals who did and did not play video games when younger.
\end{abstract}

Keywords: Cultural participation, Consumer Economics, Video games, Taste JEL Classifications: D12, J29, R12, Z11 


\section{INTRODUCTION}

Video games are regarded as one of the most significant and fastest growing form of mass media in recent years (Lenhart, 2015; Dutton and Blank, 2013). Industry analysts forecast that global video games revenue will reach $\$ 106.6$ billion in 2017 (Newzoo, 2017). Every second European plays video games and half of the players do so at least once a week (ISFE, 2012), while the generation that grew up on video games is approaching mid-life. And yet it is still debated whether playing games is a beneficial or harmful activity for individual development. A growing number of studies make use of survey data on educational and psycho-social attitudes and behaviours to examine this question and deliver mixed results (Przybylski and Mishkin, 2016). Here, we use an economic approach and a different source of data - namely, survey data on cultural participation - to see if we can detect positive or negative socio-economic impacts, including in the long run, from playing video games.

The results that we present do not indicate any obviously negative socio-economic effects of video games playing, but suggest rather the opposite: those who play are typically better educated and wealthier. ${ }^{1}$ With the gamer's average age of 43.2 years the medium cannot be characterized as "immature" and since females are on the whole more likely to play, the activity cannot be described as male-dominated. Games players are also more likely than non-games players to participate in other forms of culture, especially through active participation (e.g., creating digital video, photography or animation or writing stories or poetry), but passive participation (e.g., attending cultural festivals) is also common. These findings are reinforced when comparing the characteristics of individuals who did and did not play video games when younger. In particular, today we do not observe socio-economic differences between those who played when growing up and those who did not. We also find that those who played games when growing up participated in other forms of culture too, and in particular they were more likely to read, paint, attend performing arts and visit heritage sites and libraries.

In this paper we make two main contributions. First, availing of the very rich set of cultural variables in the Taking Part survey allows us to disclose how video games playing is related to cultural consumption by disentangling the effects of active cultural participation (e.g., writing a story or poem or painting) from more passive forms of cultural participation (e.g.,

\footnotetext{
${ }^{1}$ The data do not allow us to explore causal effects, but the correlations are robust and rather informative.
} 
attending events). Both forms of cultural engagement are often associated with positive externalities on the individual, however the former (active participation) more obviously requires or stimulates creative thinking. It therefore comes close to the priorities of cultural policy making in Europe, which focuses heavily on fostering and stimulating creativity in our societies (e.g., European Commission, 2017). Second, the paper provides unique insights on video games playing early in life and on how games playing when growing up is associated with games playing behavior later in life. In particular, the results add to the findings from studies of more traditional forms of cultural consumption that cultural tastes persist.

This paper relates thus to the important microeconomic concept of "rational addiction" (Stigler and Becker, 1977), which has had great influence in the literature on addictive behaviors. Despite the fact that a large volume of applied research on consumption patterns builds heavily on this theory (e.g., "learning-by-consuming" in Ateca-Amestoy, 2008), it has rarely been formally tested, since data on early life events is typically not available. That the Taking Part survey asks individuals to report on their cultural participation when young as well as today means that it can provide new evidence on these theories. ${ }^{2}$

Besides the core microeconomic literature, the study relates to video games research, which has been growing rapidly over the last few years. Borowiecki and Prieto-Rodriguez (2015) motivate video games playing from the perspective of cultural economics and investigate video game usage in Spain. Borowiecki and Prieto-Rodriguez (2017) explore different profiles of video games players in Denmark depending on the type of game they play. However, most academic research has focused on the supply side of the video games industry and includes analyses of video games console pricing (Cox, 2008), network effects and product cycles (Clements and Ohashi, 2005) and outcomes in competitive markets (Shankar and Bayus, 2003).

\section{DATA}

The Department of Culture, Media and Sport's (DCMS) Taking Part Survey is a continuous face to face nationally representative household survey of adults aged 16 and over in England. The survey asks respondents detailed questions about the frequency of their participation, reasons for

\footnotetext{
${ }^{2}$ Another unique feature of the data is that it allows us to illuminate the profile of video games creators. However, due to the low number of game creators, the presented analysis is only descriptive.
} 
participation, barriers to participation and attitudes in a very wide range of areas spanning the arts, museums and galleries, archives, libraries, heritage and sport. The survey also collects information on income, wealth, age, education and other economic and socio-demographic variables, and on a large number of other indicators, including cultural participation when growing up. At the suggestion of this paper's authors new questions asking about video games consumption and creation activities were introduced by the DCMS into the survey in April 2014. In this paper, we analyse responses gathered in interviews conducted between April 2014 and March 2015.

Table 1 provides descriptive statistics for those who report to play video games and those who do not. The table gives the frequency of playing for those who play and whether any of the two groups of respondent played video games when growing up and, if so, how often. It shows that one in two video games players today also played games when growing up, compared with almost one in eight who do not play nowadays but who did when younger. Both of the frequency measures in Taking Part are ordinal variables and take the following six values (we code with 6 the highest frequency): at least once a day, at least once a week, at least once a month, at least 34 times a year, at least once a year, or less often than once a year. For games players, at 5 the mean playing frequency corresponds to at least once a week nowadays, a little higher than 4.85 when growing up. When measured by the mode, average games playing frequency is higher, "at least once a day" in the case of playing today. The summary table also gives information on the age, gender, income, education, type of area of residence and physical assets of respondents (in particular whether they own a mobile phone, car or house). In addition, we present information on respondents' employment and family status. In total, there are 9,817 individuals in the Taking Part sample over this period, of which 1,455 have missing observations for income and 32 have missing observations for age.

The boxplots in Figure 1 depict the age distribution of those who do and do not play video games today and for those who did and did not play when growing up. The shaded boxes visualise the $25^{\text {th }}$ and $75^{\text {th }}$ percentiles and the vertical lines within the boxes indicate the median. Figure 1 shows that a large proportion of those who play nowadays are older: the median age of 41.5 implies that half of the population of gamers is at least in their forties, while one-fourth of players are 56 years or above. The figure also shows that those who played when growing up tend to be younger (median age of 31), and that there are in fact very few older people who 
played when growing up. This no doubt reflects the fact that video games are still a relatively young phenomenon. Taken together, the plots suggest that those who play video games either now or did so when younger are a much younger group than those who do not play games.

Figure 2 presents a scatter plot with weighted markers to visualise the frequency of playing nowadays and when growing up, and the relationship between these two variables. To denote the importance of each of the dots, their size is weighted by the relative occurrence. Owing to the disproportionately high number of respondents who do not play today and did not play when growing up (the incidence at the origin of the axes) the weight of these occurrences has been scaled down (and is shown with a shaded marker).

The figure suggests that people either do not play video games at all or, when they do they play with relatively high frequency. Nobody reports playing games when growing up with the frequency of less often than once a year and only 6 (out of 433 players when growing up) report to have played at least once a year (but less than 3-4 times a year), while only 62 respondents (out of 2,330 players) nowadays report a frequency in these two lowest frequency categories (less often than 3-4 times a year). Not all who play nowadays played when growing up, while at the same time some of those who played when growing up do not play video games today. Nonetheless, for many respondents we observe persistence in games playing frequency over time: those who played frequently when growing up tend to also to play frequently now. Using all the observations, we depict a linear fit line to estimate the correlation between these two variables, which turns out to be a statistically significant 0.27 .

Appendix 1 contains an extended summary table which presents results for the relatively small sample of 107 video games creators. This table presents data on the socio-economic background of creators and their playing probabilities. Interestingly, creators are significantly more likely than others to participate in culture, and in all but one case the difference is statistically significant at the $99 \%$ confidence interval.

\section{MODEL}

A challenge for modelling participation behaviour in cultural economics using survey data is distinguishing between individuals who report no participation in a cultural activity because they would never participate from those who do in fact have some probability of participating even 
though they have not done so in the sample period. Bagozzi et al. (2014) show that not treating these individuals as distinct groups introduces model biases (technically, the data is 'zero inflated'). One of the first studies within cultural economics that deals with this heterogeneity is Ateca-Amestoy (2008). The author measures theatre participation using count data and estimates a Zero Inflated Negative Binomial Model by characterizing two distinct behavioural groups: never-goers (who never participate) and a sub-population that has a positive probability of attending.

We estimate standard marginal effects for Probit and ordered Probit models, along with zero-inflated ordered Probit (ZIOP) models which explicitly address the challenges of a "zeroinflated" ordered dependent variable. Below we outline briefly the features of the latter model. ${ }^{3}$ The ZIOP model comprises two equations: a Probit selection equation and a standard ordered Probit. This endogenously splits the observations into two groups that exhibit potentially different associations with the explanatory variables. For the case of playing video games, respondents are assigned into one of the two groups: those who never play and are characterized always by zero consumption, and those who potentially play which may either have positive or null consumption in the period surveyed. In other words, individuals who exhibit zeroconsumption patterns are potentially attributed to two different populations. Those in the first group have no interest in video games and exhibit perfectly inelastic demand to personal constraints. Those in the second group also report zero consumption, but may consume once their constraints have been relaxed. In our models, we capture the constraints used to "inflate" the participation equation by four different variables that are intuitively associated with time commitments of a person: whether or not they are employed, self-employed, have children under the age of four and live in a household with a person older than 85 years. $^{4}$

In order to study reliably the determinants of video games playing, the choice of the underlying variables has to be conducted in line with economic theory and should also be consistent with previous research. ${ }^{5}$ We build on the established approach in the literature of using revealed preferences in order to attribute human behaviour to binding budget constraints,

\footnotetext{
${ }^{3}$ Technical details on ZIOP models can be found in Harris and Zhao (2007).

${ }^{4}$ Including instead (or in addition) a variable measuring the number of children above the age of four and below sixteen does not yield a significant coefficient for this variable (this could be a reflection of the likelihood that some parents may play video games with their older children). The baseline results remain though unchanged.

${ }^{5}$ A comprehensive review of research on cultural participation is presented by Seaman (2006).
} 
time constraints, social constraints and physical constraints and tastes. Formally, we estimate the following equation:

$V G_{i}=f\left(D_{i}, I_{i}, H C_{i}, G_{i}, P_{i}, A P_{i}, P P_{i}\right)$

The dependent variable, $V G_{i}$, is an ordinal variable and it indicates the frequency of a person playing video games as a free time activity. The explanatory variables consist of a set of socioeconomic background controls, including demographic variables $\left(D_{i}\right)$ - in our case, age and gender, and income $\left(I_{i}\right)$ - which is reflected in a 12-point ordinal scale. The equation also contains a measure of human capital $\left(H C_{i}\right)$, which is represented by an indicator function taking the value one for each category of the highest level of education obtained by the respondent. Within our framework, and in line with previous literature (see, for example, Ateca-Amestoy, 2008), the human capital variable is further used as a proxy for the 'cultural capital' of a person; that is, the personal resource accumulated by past consumption of, or exposure to, cultural experiences, and - education-based proxies aside - very difficult to quantify. Typically, education, income and occupational status are believed to be the three fundamental determinants of cultural participation (Gray et al., 2017), and the Taking Part data allows us to control for all three of these (occupation status is included in the inflation equation).

In general there exist significant differences between urban and rural areas in terms of ease of access to leisure activities. Therefore, we include a geographical control $\left(G_{i}\right)$ to indicate whether the respondent is based in an urban or rural location. Individuals who want to play video games require hardware, which we account for and label as physical capital $\left(P_{i}\right)$. Taking Part does not contain questions regarding the ownership of games consoles or personal computers, so we try and approximate the required physical capital with variables measuring whether or not the respondent owns a mobile phone, a car or a house - though these variables will also of course capture an individual's overall personal wealth.

The consumption of other cultural goods and services could conceivably also be related to video games playing. Previous research suggests this effect is positive (Borowiecki and PrietoRodriguez, 2015), however, ex ante the association is ambiguously signed. On the one hand, 
since consumption of most cultural products is costly, involvement in one activity substitutes for participation in another. On the other, cultural consumption is addictive, and with increased exposure to one cultural product, people may increase demand for complementary cultural products. We incorporate cultural consumption in the model by reflecting two types of cultural involvement: active participation $\left(A P_{i}\right)$ and passive participation $\left(P P_{i}\right)$. Active participation consists of activities, as opposed to events, whereby the individual is actively engaged and often creative involvement is required. These activities include dance (ballet or other types of dance), music (singing, performing or composing), visual arts (painting, drawing, printmaking, sculpture, including street arts), digital arts (photography or video as an artistic activity, or creation of digital art, including animation), art collection (of artworks or crafts), reading (for enjoyment), or writing (stories, plays or poetry).

The nature of passive participation - attendance at events - is arguably different, as these forms of cultural participation do not necessary require the same degree or perhaps any creative involvement. We equate passive participation with attendance at cinema, visits to events associated with video or electronic art, visual art events (street art or public art display or installation), culturally specific festivals (including circus and carnivals), performing arts events (drama and pantomime, ballet and other types of dance, opera, musicals and concerts, including classical and jazz) and visits to exhibitions (of art, photography, sculpture, craft or books).

Finally, we include in our model a set of control variables for regions to account for unobserved differences in drivers of cultural participation across England, and a set of month controls to account for any unobserved seasonal differences across the 12 months over which the survey data was collected.

\section{RESULTS}

4.1 Determinants of video games playing as a free time activity

We begin by exploring the determinants of video games playing today and estimate ZIOP models. The results are presented in Table 2, beginning with the inflation equation in column 1 (estimating the probability of ever playing) and followed by the ordered Probit equation in column 2 (estimating the frequency of playing). The basic model with a set of standard determinants is then extended in columns 3 and 4 by the inclusion of various active and passive 
cultural participation variables, while column 5 presents a standard ordered Probit model for comparison. All models include region and month fixed effects.

The probability of playing (column 1) decreases with age but at a diminishing rate, and is higher for females. The coefficient on income is positive, but statistically insignificant, suggesting that income does not constrain the incidence of playing, and the probability of playing is higher for those who are better educated. The association with urban residence is insignificant. Those who own a mobile phone or a car are more likely to play, whereas there is no statistically significant effect for those who own a house. The identifying equation is estimated properly with the chosen instruments: being employed or self-employed decreases the probability of playing, as does having children under the age of four or living in a household with a person older than 85 years. The frequency estimation (column 2) implies that age again has a negative but diminishing impact on the frequency of playing. Playing frequency is lower for females and for those with higher incomes (the latter perhaps due to access to alternative, more expensive leisure activities or because higher income individuals have a higher opportunity cost of game time). No statistically significant effect is found for educational, type of area of residence, nor measures of physical capital.

Turning to columns 3 and 4, the baseline model is extended by including the set of cultural participation variables. The likelihood ratio Chi-square of 269.9 ( $p$-value < 0.001 ) tells us that the model as a whole is statistically significant, that is, it fits significantly better than a model with no predictors. ${ }^{6}$ We also confirm that the cultural consumption variables as a group are statistically significant (with an emerging likelihood ratio chi-square of 106.9 ( $p$-value < $0.001)$.

The probability of playing (column 3) is higher for individuals who read, write (stories or poetry), are involved in creating some form of digital art (photo, video or animation), or attend festivals (festival, circus or carnival). The frequency of playing (column 4) increases for those who read, create visual art (paint or street arts), or go to the cinema, but decreases for those who attend festivals. The size and significance of the coefficients on the demographic, income and physical capital variables are broadly unchanged. However, education becomes insignificant.

\footnotetext{
${ }^{6}$ The model presented in columns 1 and 2 had a slightly lower likelihood ratio chi-square coefficient of 259.4.
} 
This supports the earlier suggestion that the education variables might proxy for cultural capital as well as formal education.

Two further observations can be made. First, the vast majority of coefficients for cultural participation are positively signed and those that are significant (discussed above) are estimated with a high degree of statistical confidence. Second, most of the significant coefficients relate to forms of active cultural participation - that is, when the individual is creating (e.g., writes stories or poetry, or creates digital art), - whereas for passive participation (e.g., attendance at art events), the coefficients are estimated with lower precision.

The final column reports an ordered Probit model that depicts the correlates of the probability of video games playing. The background variables are estimated to be consistent with the ZIOP models. While the correlation coefficients for some of the cultural activities change, the previous observation that primary active cultural participation is significantly and positively related to playing frequency remains robust.

4.2 Video games playing when growing up

The Taking Part Survey contains several questions asking respondents about their cultural participation when growing up, including whether they played "video/computer games on a digital device like a console, a computer, a tablet or a mobile phone". This question was asked of half of the sample and responses are available for 4,827 respondents. Columns 1 and 2 of Table 3 present the marginal effects for a Probit model. ${ }^{7}$

The point estimates are negative for age, indicating that those who played when growing up are younger nowadays. Female are less likely to have played when growing up: the probability of women having played when growing up is $7.9 \%$ lower than for men, all else equal. Those who played when growing up tend to have obtained better educational qualifications, but are less likely to own a house.

In the next column we introduce the available measures for cultural participation when growing up. While the estimates for age and female remain broadly unchanged, the association

\footnotetext{
${ }^{7}$ It is not possible to utilize a ZIOP model in this setting due to the lack of adequate variables that could be used in the inflation equation (i.e., nothing is known about the respondents' socio-economic characteristics when growing up).
} 
with higher education nowadays disappears. This could once again be an artefact of the complementary association between human capital and cultural capital, which is likely to have accumulated through exposure to various cultural activities when growing up. Thus this finding provides some support to the idea (e.g., Ateca-Amestoy, 2008) that education attainment serves as a proxy for cultural capital. The coefficients for cultural consumption when growing up turn mostly positive and statistically significant in five out of eight cases, suggesting that individuals who played video games when growing up, were also significantly more likely to be involved in other cultural activities. In particular, those who played were more likely to read for pleasure, paint or draw, attend performing arts (go to theatre, dance or classical music performances), visit historic sites or libraries. These results are in line not only with the baseline results, but illuminate also a striking persistence in the preferences and behaviours of the respondents. In particular, those who play video games consume more culture, and this relationship was true earlier in life, as it is nowadays.

It may come as a surprise to some readers that the included socio-economic variables do not obviously indicate any harmful long-term effects of video games playing. The differences in income, educational attainment, place of residence or wealth between those who have and have not played when growing up are mostly statistically insignificant. With the exception of the negative coefficient for house ownership, the variables that turn significant in one of the two models suggest, if anything, the existence of positive correlations. For example, those who have played when growing up have likely obtained nowadays more advanced educational qualifications. These are very general associations and some degree of caution is required in their interpretation, nonetheless, the results confront the stereotypical perception about harmful effects of video games playing.

\subsection{Persistence in video games playing}

We turn next to the analysis of the effects of video games playing when growing up on playing behaviour today. For this reason, we estimate Probit models with the probability of playing nowadays a function of the various measures of cultural participation, including video games playing when growing up. The models contain control variables for individuals' socio-economic backgrounds, regions and month (not reported). 
In column 1 of Table 4 we include first the dummy variable indicating whether or not the respondent was playing video games when growing up and present the marginal effects. The point estimate is positive, highly significant and rather large, implying that those who have played when growing up are $27.3 \%$ more likely to play nowadays.

Next, the model is extended in column 2 by including indicators of other forms of cultural participation when growing up. We find several positive and significant associations between video games playing today and the newly added variables. In particular, the probability of playing nowadays is higher for those who wrote (stories, poems, plays or music), performed (acted, played musical instrument, sung or danced), and visited historic sites (e.g., heritage buildings, historic parks and gardens and archaeological sites). We note that the estimated effect of playing video games when growing on playing today remains stable and is also the largest in size. This supports the significant and positive association between playing nowadays and when growing up.

Finally, we explore whether video games playing today and when growing up differ depending on the frequency of each of the involvements. However, the data present a challenge in this regard, since the question about the frequency is asked of individuals only in relation to one of their activities when growing up. For individuals who have participated in more than one cultural activity when growing up, the frequency question is asked for only one randomly selected activity. This means that of the 1,101 positive occurrences of playing when growing up we obtain frequency data only for 433 cases. To be able to use this in econometric analysis, we need to construct a random sample of an identical weight for the negative cases, that is, those who do not play when growing up. We then repeat this sampling procedure with replacement 50 times in order to obtain the bootstrap estimates of the standard errors. Using the obtained frequency of playing measures, we estimate in column 3 a model in which we estimate the effect of the frequency of playing when growing up on the frequency of playing today. The point estimates are positive and again highly significant, implying that those who played more frequently when growing up play also more often nowadays.

4.4 Robustness of the results 
We begin by assessing whether our results hold when we control for access to the Internet, which could be related to playing video games in at least two ways. First, having internet access increases the attraction of playing, since online gaming (i.e., playing with other people via the Internet) becomes possible. ${ }^{8}$ Second, with internet access, greater information about the latest video games becomes available - whether via formal advertisement channels or through social networks - and this may increase consumption.

The baseline ZIOP models are re-estimated using additional control variables to account for the respondent's use or type of access to the Internet. Table 5 shows that the baseline results (repeated in columns 1 and 2 of Table 5) remain broadly unchanged if we add dummy variables for whether or not the individual uses the Internet in her spare time (columns 3 and 4), or has accessed the Internet at home using a computer, a games console, a mobile device or a portable games console (columns 5 and 6). As expected, the coefficient estimates for each of these additional control variables are positive and highly significant.

We also explore the existence of any difference between those who play or those who play more often, with regard to nationality, ethnic or religious background, or sexual orientation, but do not find any significant effects of these variables. Nor does inclusion of these variables as additional controls alter the baseline findings. ${ }^{9}$

\section{CONCLUSIONS}

Playing video games has come of age as a leisure activity, and the generation that grew up on video games is now reaching mid-life. Yet, despite the growing number of studies using survey data on educational and psycho-social attitudes and behaviours to examine the impact of games playing on personal development, a consensus remains lacking. This study has made use of a novel data set - drawn from a national survey of cultural participation in England - to examine the socio-economic characteristics of games players and their wider cultural preoccupations. Furthermore, the structure of the Taking Part Survey allows us to look at the longer term patterns of video games playing, and in particular its persistence over time.

\footnotetext{
${ }^{8}$ See, for example, Castronova (2001) for an overview of the extent and potential of online video games playing.

${ }^{9}$ Results are available from the authors on request.
} 
The results, first of all, do not reveal any obviously negative associations with socioeconomic variables. If anything, those who play games are typically better educated, wealthier and are greater consumers of culture. The presented correlations are not proof of causal relationships; nonetheless, the results challenge the stereotypical perception that video games playing has harmful effects on the individual. While there is some evidence that more frequent games playing is associated with lower income, several explanations are consistent with this finding (including the possibility that individuals with lower incomes have a lower opportunity cost of spending time playing video games).

Neither do the results lend any support to the idea that playing video games has longer term detrimental impacts on an individual's socio-economic circumstances. That is, in general, we do not observe any socio-economic differences between those who played when growing up and those who did not. Interestingly, we find that those who played when growing up also participated in other forms of culture, in particular, they were more likely to read, paint, attend performing arts and visit heritage sites or libraries. We also observe a path-dependency in playing video games: those who played when growing up are also more likely to do so nowadays. A general caveat that applies to these results, however, is that it is not clear what life period is meant by the time when one is "growing up", nor is there any reason to expect survey respondents to have answered this consistently.

Third, although we confirm that video games playing is more popular among younger individuals, with the gamer's average age in Taking Part of 43.2 years, the recurring perception that the medium is "immature" is far from being supported. Interestingly, the average gamer is more likely to be female, however among those who play, females do so less often than males.

The study delivers several insights which may have implications for policy makers. The results provide further support for the view that involvement in cultural activities when growing up corresponds with accumulation of cultural capital and has significant path dependencies over the course of life. Cultural policy makers may therefore be right to focus so much on the behaviours of young people. The complementarities we have detected between games playing and other forms of cultural participation may however challenge policy makers' conceptions of what constitutes 'culture' from the viewpoint of policy (Bakhshi and Cunningham, 2016). 
An important question is whether video games playing makes people more creative. This is a matter we are unfortunately unable to address properly with the data used here. We observe, however, that those who play video games have a stronger tendency to engage in more active forms of cultural activity which is consistent at least with greater creativity. However, it remains an open question whether this finding is a reflection of a creativity-enhancing effect of playing video games, or is rather driven by self-selection of a certain type of person towards both activities - video games playing and active forms of cultural participation. 


\section{References}

Ateca-Amestoy, V. M. (2008). Determining heterogeneous behavior for theater attendance. Journal of Cultural Economics, 32(2), 127-151.

Bagozzi, Benjamin E., Daniel W. Hill, Jr, Will H. Moore, Bumba Mukherjee (2014) Modeling Two Types of Peace. Journal of Conflict Resolution, 59(4), 728-752

Bakhshi, H. and Cunningham, S. (2016). Cultural Policy in the Time of the Creative Industries. Nesta Provocation.

Borowiecki, Karol J. and Juan Prieto-Rodriguez (2015). Video Games Playing: A substitute for cultural consumptions?, Journal of Cultural Economics, 39(3): 239-58

Borowiecki, Karol J. and Juan Prieto-Rodriguez (2017). The Cultural Value and Variety of Video Games Playing. In J. Prieto-Rodriguez, V.M. Ateca-Amestoy, V. Ginsburgh, I. Mazza and J. O'Hagan (Eds.), Enhancing Cultural Participation in the EU. Challenges and Methods. Heidelberg: Springer, forthcoming.

Castronova, E. (2001). Virtual Worlds: A First-Hand Account of Market and Society on the Cyberian Frontier. CESifo Working Paper Series, No 618.

Clements, M. T. \& Ohashi, H. (2005). Indirect network effects and the product cycle: video games in the US, 1994-2002. Journal of Industrial Economics, 53, 515-42.

Cox, J. (2008). Purchasing power parity and cultural convergence: evidence from the global video games market. Journal of Cultural Economics, 32(3), 201-214.

Dutton, W.H. and Blank, G., with Groselj, D. (2013) Cultures of the Internet: The Internet in Britain. Oxford Internet Survey 2013. Oxford Internet Institute, University of Oxford

European Commission - Creative Europe (2017). Supporting cultural and creative industries. http://ec.europa.eu/culture/policy/cultural-creative-industries_en (Accessed $15^{\text {th }}$ March 2017).

Gray, Charles M., Karol J. Borowiecki and James Heilbrun (2017). The Economics of Art and Culture. Cambridge University Press.

Harris, M. N., \& Zhao, X. (2007). A zero-inflated ordered probit model, with an application to modelling tobacco consumption. Journal of Econometrics, 141(2), 1073-1099.

ISFE. Interactive Software Federation of Europe (2012). Videogames in Europe: Consumer Study. European Summary Report. Brussels: Ipsos MediaCT.

Lenhart, A. (2015). Teen, Social Media and Technology Overview 2015, Pew Research Center. 
Newzoo (2017) https://newzoo.com/insights/markets/games/ (last accessed 18 March 2017).

Przybylski, A. and Mishkin, A. (2016). How the quantity and quality of electronic gaming relates to adolescents' academic engagement and psychosocial adjustment. Psychology of Popular Media Culture, Vol 5(2): 145-156.

Seaman, B. A. (2006). Empirical studies of demand for the performing arts. In V. A. Ginsburg, \& D. Throsby (Eds.), Handbook on the Economics of Art and Culture (Vol. 1, pp. 415472). Amsterdam: Elsevier.

Shankar, V., \& Bayus, B. L. (2003). Network effects and competition: an empirical analysis of the home video game industry. Strategic Management Journal, 24(4), 375-384.

Stigler, G. J., \& Becker, G. S. (1977). De gustibus non est disputandum. American Economic Review, 67(2), 76-90. 
Tables

Table 1. Summary statistics

\begin{tabular}{|c|c|c|c|c|c|c|c|c|}
\hline & \multicolumn{3}{|c|}{ Gamers } & \multicolumn{3}{|c|}{ Non-gamers } & \multicolumn{2}{|c|}{ Difference } \\
\hline & Obs & Mean & Std. Dev. & Obs & Mean & Std. Dev. & & \\
\hline vg_play & 2333 & 1 & 0 & 7484 & 0 & 0 & & \\
\hline vg_freq & 2330 & 5.01 & 1.06 & 7484 & 0 & 0 & 5.01 & $*$ \\
\hline vg_growing & 1220 & 0.50 & 0.50 & 3607 & 0.13 & 0.34 & 0.37 & $*$ \\
\hline vg_grow_fr & 230 & 4.85 & 0.92 & 203 & 4.54 & 0.89 & 0.31 & $*$ \\
\hline age & 2330 & 43.20 & 16.96 & 7455 & 56.58 & 17.84 & -13.39 & $*$ \\
\hline female & 2333 & 0.51 & 0.50 & 7484 & 0.57 & 0.49 & -0.06 & $*$ \\
\hline income & 2038 & 5.36 & 2.95 & 6324 & 5.29 & 2.88 & 0.07 & \\
\hline educ1_other & 2333 & 0.02 & 0.16 & 7484 & 0.05 & 0.21 & -0.02 & $*$ \\
\hline educ2_appr e & 2333 & 0.03 & 0.16 & 7484 & 0.05 & 0.22 & -0.02 & $*$ \\
\hline educ3_GCSE 4 & 2333 & 0.06 & 0.23 & 7484 & 0.05 & 0.22 & 0.01 & \\
\hline educ4_GCSE_5 & 2333 & 0.18 & 0.38 & 7484 & 0.13 & 0.34 & 0.05 & $*$ \\
\hline educ5_A_le $\sim$ s & 2333 & 0.21 & 0.41 & 7484 & 0.15 & 0.36 & 0.05 & $*$ \\
\hline educ6_high d & 2333 & 0.11 & 0.32 & 7484 & 0.10 & 0.31 & 0.01 & \\
\hline educ7_high e & 2333 & 0.28 & 0.45 & 7484 & 0.25 & 0.43 & 0.04 & $*$ \\
\hline urban & 2333 & 0.81 & 0.40 & 7484 & 0.79 & 0.41 & 0.02 & $*$ \\
\hline wealth_mobile & 2332 & 0.97 & 0.17 & 7476 & 0.88 & 0.33 & 0.09 & $*$ \\
\hline wealth_car & 2333 & 0.82 & 0.39 & 7484 & 0.78 & 0.42 & 0.04 & $*$ \\
\hline wealth_house & 2333 & 0.26 & 0.44 & 7484 & 0.43 & 0.50 & -0.17 & $*$ \\
\hline empl_selfe 1 & 2333 & 0.08 & 0.27 & 7484 & 0.07 & 0.26 & 0.01 & \\
\hline empl_emplo d & 2333 & 0.51 & 0.50 & 7484 & 0.38 & 0.48 & 0.14 & $*$ \\
\hline living_cou e & 2333 & 0.56 & 0.50 & 7484 & 0.56 & 0.50 & 0.00 & \\
\hline nchild_0_4 & 2333 & 0.19 & 0.48 & 7484 & 0.13 & 0.41 & 0.07 & $*$ \\
\hline nadults_85 & 2333 & 0.00 & 0.06 & 7484 & 0.01 & 0.12 & -0.01 & $*$ \\
\hline
\end{tabular}

$* \mathrm{p}<0.05$ 
Table 2. Determinants of video games playing as a free time activity

\begin{tabular}{|c|c|c|c|c|c|}
\hline & $\begin{array}{c}(1) \\
\text { ZIOP } \\
\text { vg_play }\end{array}$ & $\begin{array}{c}(2) \\
\text { ZIOP } \\
\text { vg_freq }\end{array}$ & $\begin{array}{c}\text { (3) } \\
\text { ZIOP } \\
\text { vg_play }\end{array}$ & $\begin{array}{c}(4) \\
\text { ZIOP } \\
\text { vg_freq }\end{array}$ & $\begin{array}{c}(5) \\
\text { Ordered } \\
\text { Probit } \\
\text { vg_play }\end{array}$ \\
\hline age & $\begin{array}{c}-0.140 * * * \\
(0.0218)\end{array}$ & $\begin{array}{c}-0.0678 * * * \\
(0.0129)\end{array}$ & $\begin{array}{c}-0.144 * * * \\
(0.0221)\end{array}$ & $\begin{array}{c}-0.0607 * * * \\
(0.0121)\end{array}$ & $\begin{array}{c}-0.0125^{* *} \\
(0.00509)\end{array}$ \\
\hline age2_100 & $\begin{array}{c}0.0676^{* * * *} \\
(0.0164)\end{array}$ & $\begin{array}{c}0.100 * * * \\
(0.0150)\end{array}$ & $\begin{array}{c}0.0729 * * * \\
(0.0166)\end{array}$ & $\begin{array}{c}0.0866 * * * \\
(0.0150)\end{array}$ & $\begin{array}{l}-0.00641 \\
(0.00519)\end{array}$ \\
\hline female & $\begin{array}{c}0.432 * * * \\
(0.0728)\end{array}$ & $\begin{array}{c}-0.644 * * * \\
(0.0616)\end{array}$ & $\begin{array}{c}0.365^{* * *} * \\
(0.0829)\end{array}$ & $\begin{array}{c}-0.646^{* * *} \\
(0.0635)\end{array}$ & $\begin{array}{c}-0.197 * * * \\
(0.0339)\end{array}$ \\
\hline income & $\begin{array}{c}0.0142 \\
(0.0133)\end{array}$ & $\begin{array}{c}-0.0297 * * * \\
(0.0108)\end{array}$ & $\begin{array}{c}0.0198 \\
(0.0143)\end{array}$ & $\begin{array}{c}-0.0358 * * * \\
(0.0108)\end{array}$ & $\begin{array}{c}-0.0211 * * * * \\
(0.00614)\end{array}$ \\
\hline educ1_other & $\begin{array}{l}-0.274 \\
(0.172)\end{array}$ & $\begin{array}{c}0.269 \\
(0.246)\end{array}$ & $\begin{array}{c}-0.300 * \\
(0.171)\end{array}$ & $\begin{array}{c}0.197 \\
(0.235)\end{array}$ & $\begin{array}{c}-0.118 \\
(0.0979)\end{array}$ \\
\hline educ2_apprentice & $\begin{array}{l}-0.138 \\
(0.148)\end{array}$ & $\begin{array}{l}0.0285 \\
(0.204)\end{array}$ & $\begin{array}{l}-0.181 \\
(0.151)\end{array}$ & $\begin{array}{l}-0.0199 \\
(0.204)\end{array}$ & $\begin{array}{l}-0.222 * * \\
(0.0948)\end{array}$ \\
\hline educ3_GCSE_1_4 & $\begin{array}{c}0.196 \\
(0.148)\end{array}$ & $\begin{array}{c}-0.0675 \\
(0.149)\end{array}$ & $\begin{array}{c}0.194 \\
(0.154)\end{array}$ & $\begin{array}{l}-0.117 \\
(0.148)\end{array}$ & $\begin{array}{c}0.0935 \\
(0.0774)\end{array}$ \\
\hline educ4_GCSE_5 & $\begin{array}{c}0.263 * * \\
(0.108)\end{array}$ & $\begin{array}{l}-0.0105 \\
(0.119)\end{array}$ & $\begin{array}{c}0.239 * * \\
(0.114)\end{array}$ & $\begin{array}{c}-0.0692 \\
(0.119)\end{array}$ & $\begin{array}{l}0.134 * * \\
(0.0597)\end{array}$ \\
\hline educ5_A_levels & $\begin{array}{l}0.185^{*} \\
(0.104)\end{array}$ & $\begin{array}{c}-0.00895 \\
(0.116)\end{array}$ & $\begin{array}{c}0.147 \\
(0.109)\end{array}$ & $\begin{array}{l}-0.0949 \\
(0.116)\end{array}$ & $\begin{array}{c}0.0423 \\
(0.0591)\end{array}$ \\
\hline educ6_high_ed & $\begin{array}{c}0.269 * * \\
(0.115)\end{array}$ & $\begin{array}{c}-0.0545 \\
(0.128)\end{array}$ & $\begin{array}{c}0.173 \\
(0.124)\end{array}$ & $\begin{array}{l}-0.136 \\
(0.128)\end{array}$ & $\begin{array}{c}0.0482 \\
(0.0656)\end{array}$ \\
\hline educ7_high_ed_degree & $\begin{array}{l}0.222^{* *} \\
(0.0997)\end{array}$ & $\begin{array}{c}-0.00851 \\
(0.116)\end{array}$ & $\begin{array}{l}0.0740 \\
(0.111)\end{array}$ & $\begin{array}{l}-0.104 \\
(0.118)\end{array}$ & $\begin{array}{l}-0.0276 \\
(0.0597)\end{array}$ \\
\hline urban & $\begin{array}{c}0.045 \\
(0.0757)\end{array}$ & $\begin{array}{l}-0.0047 \\
(0.0697)\end{array}$ & $\begin{array}{c}0.0901 \\
(0.0804)\end{array}$ & $\begin{array}{l}-0.0377 \\
(0.0706)\end{array}$ & $\begin{array}{c}0.0155 \\
(0.0398)\end{array}$ \\
\hline wealth_mobile & $\begin{array}{c}0.436 * * * \\
(0.107)\end{array}$ & $\begin{array}{l}-0.257 \\
(0.201)\end{array}$ & $\begin{array}{c}0.426^{* * *} * \\
(0.109)\end{array}$ & $\begin{array}{l}-0.273 \\
(0.201)\end{array}$ & $\begin{array}{c}0.248 * * * \\
(0.0744)\end{array}$ \\
\hline wealth_car & $\begin{array}{l}0.169 * * \\
(0.0844)\end{array}$ & $\begin{array}{l}-0.0320 \\
(0.0675)\end{array}$ & $\begin{array}{l}0.178 * * \\
(0.0889)\end{array}$ & $\begin{array}{l}-0.0431 \\
(0.0674)\end{array}$ & $\begin{array}{c}0.0209 \\
(0.0424)\end{array}$ \\
\hline wealth_house & $\begin{array}{c}0.0531 \\
(0.0787)\end{array}$ & $\begin{array}{l}-0.0580 \\
(0.0886)\end{array}$ & $\begin{array}{c}0.0215 \\
(0.0826)\end{array}$ & $\begin{array}{l}-0.0278 \\
(0.0895)\end{array}$ & $\begin{array}{c}0.0372 \\
(0.0412)\end{array}$ \\
\hline ap_read & & & $\begin{array}{l}0.162 * * \\
(0.0722)\end{array}$ & $\begin{array}{c}0.103 * \\
(0.0578)\end{array}$ & $\begin{array}{c}0.130 * * * \\
(0.0352)\end{array}$ \\
\hline ap_write & & & $\begin{array}{c}0.351 * * \\
(0.156)\end{array}$ & $\begin{array}{l}-0.139 \\
(0.102)\end{array}$ & $\begin{array}{c}0.0346 \\
(0.0678)\end{array}$ \\
\hline ap_visual & & & $\begin{array}{c}0.152 \\
(0.101)\end{array}$ & $\begin{array}{c}0.118 * \\
(0.0673)\end{array}$ & $\begin{array}{l}0.116^{* *} \\
(0.0454)\end{array}$ \\
\hline
\end{tabular}




\begin{tabular}{|c|c|c|c|c|c|}
\hline ap_digital & & & $\begin{array}{c}0.261 * * * \\
(0.100)\end{array}$ & $\begin{array}{c}0.0675 \\
(0.0732)\end{array}$ & $\begin{array}{c}0.138 * * * \\
(0.0459)\end{array}$ \\
\hline \multirow[t]{2}{*}{ ap_dance } & & & 0.162 & -0.0915 & -0.0240 \\
\hline & & & $(0.107)$ & $(0.0692)$ & $(0.0452)$ \\
\hline \multirow[t]{2}{*}{ ap_music } & & & -0.0592 & 0.0425 & 0.0248 \\
\hline & & & $(0.0952)$ & $(0.0745)$ & $(0.0464)$ \\
\hline \multirow[t]{2}{*}{ ap_perform } & & & 0.167 & 0.116 & $0.133^{*}$ \\
\hline & & & $(0.185)$ & $(0.115)$ & $(0.0801)$ \\
\hline \multirow[t]{2}{*}{ ap_collect } & & & 0.121 & 0.0690 & $0.118 * * *$ \\
\hline & & & $(0.0889)$ & $(0.0687)$ & $(0.0420)$ \\
\hline \multirow[t]{2}{*}{ pp_cinema } & & & 0.00242 & $0.251 * * *$ & $0.158 * * *$ \\
\hline & & & $(0.0715)$ & $(0.0583)$ & $(0.0345)$ \\
\hline \multirow[t]{2}{*}{ pp_visual } & & & 0.0555 & 0.0304 & $0.0843^{*}$ \\
\hline & & & $(0.0903)$ & $(0.0721)$ & $(0.0438)$ \\
\hline \multirow[t]{2}{*}{ pp_digital } & & & 0.0600 & -0.0433 & -0.00347 \\
\hline & & & $(0.198)$ & $(0.131)$ & $(0.0869)$ \\
\hline \multirow[t]{2}{*}{ pp_perf_all } & & & -0.0507 & 0.0136 & -0.0189 \\
\hline & & & $(0.0701)$ & $(0.0563)$ & $(0.0344)$ \\
\hline \multirow[t]{2}{*}{ pp_festival } & & & $0.329 * * *$ & $-0.127 * *$ & 0.0376 \\
\hline & & & $(0.0960)$ & $(0.0634)$ & $(0.0402)$ \\
\hline \multirow[t]{2}{*}{ pp_exhibit_all } & & & -0.124 & -0.0989 & $-0.0968 * *$ \\
\hline & & & $(0.0816)$ & $(0.0687)$ & $(0.0413)$ \\
\hline \multirow[t]{2}{*}{ empl_selfempl } & $-0.340 * * *$ & & $-0.410 * * *$ & & \\
\hline & $(0.102)$ & & $(0.112)$ & & \\
\hline \multirow[t]{2}{*}{ empl_employed } & $-0.186^{* * *}$ & & $-0.213^{* * *}$ & & \\
\hline & $(0.0694)$ & & $(0.0771)$ & & \\
\hline \multirow[t]{2}{*}{ living_couple } & 0.0582 & & 0.0603 & & \\
\hline & $(0.0539)$ & & $(0.0592)$ & & \\
\hline \multirow[t]{2}{*}{ nchild_0_4 } & $-0.237 * *$ & & $-0.216^{*}$ & & \\
\hline & $(0.0959)$ & & $(0.111)$ & & \\
\hline \multirow[t]{2}{*}{ nadults_85 } & $-0.625 * *$ & & $-0.626^{*}$ & & \\
\hline & $(0.309)$ & & $(0.330)$ & & \\
\hline Observations & 8,344 & 8,344 & 8,344 & 8,344 & 8,344 \\
\hline Month controls & yes & yes & yes & yes & yes \\
\hline Region controls & yes & yes & yes & yes & yes \\
\hline
\end{tabular}

Standard errors in parentheses. $* * * \mathrm{p}<0.01, * * \mathrm{p}<0.05, * \mathrm{p}<0.1$ 
Table 3. Video games playing when growing up

\begin{tabular}{|c|c|c|}
\hline & $\begin{array}{c}\text { (1) } \\
\text { Probit } \\
\text { (marginal) } \\
\text { vg_growing }\end{array}$ & $\begin{array}{c}\text { (2) } \\
\text { Probit } \\
\text { (marginal) } \\
\text { vg_growing }\end{array}$ \\
\hline age & $\begin{array}{c}0.00141 \\
(0.00140)\end{array}$ & $\begin{array}{c}0.00176 \\
(0.00122)\end{array}$ \\
\hline age2_100 & $\begin{array}{c}-0.0104 * * * \\
(0.00117)\end{array}$ & $\begin{array}{c}-0.0100 * * * \\
(0.00107)\end{array}$ \\
\hline female & $\begin{array}{c}-0.0788 * * * \\
(0.0126)\end{array}$ & $\begin{array}{c}-0.0834 * * * \\
(0.0138)\end{array}$ \\
\hline income & $\begin{array}{l}0.000861 \\
(0.00102)\end{array}$ & $\begin{array}{c}0.000715 \\
(0.000919)\end{array}$ \\
\hline educ1_other & $\begin{array}{l}-0.0134 \\
(0.0170)\end{array}$ & $\begin{array}{l}-0.0175 \\
(0.0129)\end{array}$ \\
\hline educ2_apprentice & $\begin{array}{c}0.0235 \\
(0.0256)\end{array}$ & $\begin{array}{c}0.0106 \\
(0.0202)\end{array}$ \\
\hline educ3_GCSE_1_4 & $\begin{array}{c}0.0329 \\
(0.0229)\end{array}$ & $\begin{array}{c}0.0216 \\
(0.0192)\end{array}$ \\
\hline educ4_GCSE_5 & $\begin{array}{c}0.0184 \\
(0.0157)\end{array}$ & $\begin{array}{l}0.00611 \\
(0.0126)\end{array}$ \\
\hline educ5_A_levels & $\begin{array}{l}0.0303 * \\
(0.0170)\end{array}$ & $\begin{array}{c}0.0104 \\
(0.0131)\end{array}$ \\
\hline educ6_high_ed & $\begin{array}{c}0.0230 \\
(0.0179)\end{array}$ & $\begin{array}{l}0.00501 \\
(0.0133)\end{array}$ \\
\hline educ7_high_ed_degree & $\begin{array}{l}0.0290 * \\
(0.0155)\end{array}$ & $\begin{array}{l}0.00385 \\
(0.0118)\end{array}$ \\
\hline urban & $\begin{array}{c}0.00806 \\
(0.00686)\end{array}$ & $\begin{array}{c}0.00589 \\
(0.00624)\end{array}$ \\
\hline wealth_mobile & $\begin{array}{c}-4.77 \mathrm{e}-05 \\
(0.0187)\end{array}$ & $\begin{array}{c}-4.26 \mathrm{e}-05 \\
(0.0170)\end{array}$ \\
\hline wealth_car & $\begin{array}{c}0.00756 \\
(0.00662)\end{array}$ & $\begin{array}{c}0.00694 \\
(0.00597)\end{array}$ \\
\hline wealth_house & $\begin{array}{l}-0.0154 * \\
(0.00891)\end{array}$ & $\begin{array}{c}-0.0129 \\
(0.00808)\end{array}$ \\
\hline grow_read & & $\begin{array}{l}0.0114 * * \\
(0.00549)\end{array}$ \\
\hline grow_write & & $\begin{array}{l}-0.00111 \\
(0.00552)\end{array}$ \\
\hline grow_paint & & $\begin{array}{l}0.0123 * * \\
(0.00562)\end{array}$ \\
\hline
\end{tabular}




\begin{tabular}{lc} 
grow_perform & 0.00812 \\
& $(0.00555)$ \\
grow_attend & $0.0109 *$ \\
& $(0.00604)$ \\
grow_museum & 0.00464 \\
& $(0.00595)$ \\
grow_heritage & $0.0110^{*}$ \\
& $(0.00606)$ \\
grow_library & $0.0102 *$ \\
& $(0.00608)$ \\
& \\
Observations & 3,992 \\
Month controls & yes \\
Region controls & 3,992 \\
\hline Standard errors in parentheses. $* * * p<0.01, * * p<0.05, *$ \\
p<0.1 & yes
\end{tabular}


Table 4. Persistency in video games playing

\begin{tabular}{|c|c|c|c|}
\hline & $\begin{array}{c}(1) \\
\text { Probit } \\
\text { (marginal) } \\
\text { vg_play }\end{array}$ & $\begin{array}{c}(2) \\
\text { Probit } \\
\text { (marginal) } \\
\text { vg_play }\end{array}$ & $\begin{array}{c}(3) \\
\text { Ordered } \\
\text { probit } \\
\text { vg_freq }\end{array}$ \\
\hline vg_growing & $\begin{array}{c}0.273^{* * *} * \\
(0.0228)\end{array}$ & $\begin{array}{c}0.263 * * * \\
(0.0229)\end{array}$ & \\
\hline grow_read & & $\begin{array}{c}0.00698 \\
(0.0173)\end{array}$ & \\
\hline grow_write & & $\begin{array}{c}0.0363 * * \\
(0.0170)\end{array}$ & \\
\hline grow_paint & & $\begin{array}{l}0.00417 \\
(0.0152)\end{array}$ & \\
\hline grow_perform & & $\begin{array}{c}0.0347 * * \\
(0.0156)\end{array}$ & \\
\hline grow_attend & & $\begin{array}{r}-0.00731 \\
(0.0163)\end{array}$ & \\
\hline grow_museum & & $\begin{array}{l}-0.0139 \\
(0.0176)\end{array}$ & \\
\hline grow_heritage & & $\begin{array}{c}0.0666 * * * \\
(0.0172)\end{array}$ & \\
\hline grow_library & & $\begin{array}{c}0.0156 \\
(0.0188)\end{array}$ & \\
\hline vg_grow_fr & & & $\begin{array}{c}0.119 * * * \\
(0.0231)\end{array}$ \\
\hline Observations & 3,992 & 3,992 & 1,572 \\
\hline Socio-economic controls & yes & yes & yes \\
\hline Month controls & yes & yes & yes \\
\hline Region controls & yes & yes & yes \\
\hline
\end{tabular}

Standard errors in parentheses. $* * * \mathrm{p}<0.01, * * \mathrm{p}<0.05, * \mathrm{p}<0.1$ 
Table 5. Robustness tests

\begin{tabular}{|c|c|c|c|c|c|c|}
\hline & $\begin{array}{c}\text { (1) } \\
\text { ZIOP } \\
\text { Baseline } \\
\text { vg_play }\end{array}$ & $\begin{array}{c}(2) \\
\text { ZIOP } \\
\text { Baseline } \\
\text { vg_freq }\end{array}$ & $\begin{array}{c}\text { (3) } \\
\text { ZIOP } \\
\text { Internet use } \\
\text { vg_play }\end{array}$ & $\begin{array}{c}(4) \\
\text { ZIOP } \\
\text { Internet } \\
\text { use } \\
\text { vg_freq }\end{array}$ & $\begin{array}{c}(5) \\
\text { ZIOP } \\
\text { Internet } \\
\text { access } \\
\text { vg_play }\end{array}$ & $\begin{array}{c}(6) \\
\text { ZIOP } \\
\text { Internet } \\
\text { access } \\
\text { vg_freq }\end{array}$ \\
\hline age & $\begin{array}{c}-0.0607 * * * \\
(0.0121)\end{array}$ & $\begin{array}{c}-0.144 * * * \\
(0.0221)\end{array}$ & $\begin{array}{c}-0.0553 * * * \\
(0.0121)\end{array}$ & $\begin{array}{c}-0.144 * * * \\
(0.0223)\end{array}$ & $\begin{array}{c}-0.0552^{* * *} \\
(0.0119)\end{array}$ & $\begin{array}{c}-0.143 * * * \\
(0.0279)\end{array}$ \\
\hline age2_100 & $\begin{array}{c}0.0866^{* * *} \\
(0.0150)\end{array}$ & $\begin{array}{c}0.0729 * * * \\
(0.0166)\end{array}$ & $\begin{array}{c}0.0802 * * * \\
(0.0146)\end{array}$ & $\begin{array}{c}0.0780 * * * \\
(0.0169)\end{array}$ & $\begin{array}{c}0.0807 * * * \\
(0.0149)\end{array}$ & $\begin{array}{c}0.0801 * * * \\
(0.0204)\end{array}$ \\
\hline female & $\begin{array}{c}-0.646 * * * \\
(0.0635)\end{array}$ & $\begin{array}{c}0.365 * * * \\
(0.0829)\end{array}$ & $\begin{array}{c}-0.647 * * * \\
(0.0644)\end{array}$ & $\begin{array}{c}0.367 * * * \\
(0.0875)\end{array}$ & $\begin{array}{c}-0.512 * * * \\
(0.0624)\end{array}$ & $\begin{array}{c}0.347 * * * \\
(0.0880)\end{array}$ \\
\hline income & $\begin{array}{c}-0.0358 * * * \\
(0.0108)\end{array}$ & $\begin{array}{c}0.0198 \\
(0.0143)\end{array}$ & $\begin{array}{c}-0.0391 * * * \\
(0.0109)\end{array}$ & $\begin{array}{c}0.0136 \\
(0.0145)\end{array}$ & $\begin{array}{c}-0.0386^{* * *} \\
(0.0105)\end{array}$ & $\begin{array}{c}-0.000679 \\
(0.0155)\end{array}$ \\
\hline educ1_other & $\begin{array}{c}0.197 \\
(0.235)\end{array}$ & $\begin{array}{l}-0.300^{*} \\
(0.171)\end{array}$ & $\begin{array}{c}0.202 \\
(0.238)\end{array}$ & $\begin{array}{c}-0.385 * * \\
(0.175)\end{array}$ & $\begin{array}{c}0.186 \\
(0.225)\end{array}$ & $\begin{array}{c}-0.356^{* * *} \\
(0.178)\end{array}$ \\
\hline educ2_apprentice & $\begin{array}{l}-0.0199 \\
(0.204)\end{array}$ & $\begin{array}{l}-0.181 \\
(0.151)\end{array}$ & $\begin{array}{l}-0.0618 \\
(0.204)\end{array}$ & $\begin{array}{l}-0.241 \\
(0.158)\end{array}$ & $\begin{array}{l}-0.0951 \\
(0.195)\end{array}$ & $\begin{array}{l}-0.220 \\
(0.164)\end{array}$ \\
\hline educ3_GCSE_1_4 & $\begin{array}{l}-0.117 \\
(0.148)\end{array}$ & $\begin{array}{c}0.194 \\
(0.154)\end{array}$ & $\begin{array}{l}-0.123 \\
(0.149)\end{array}$ & $\begin{array}{c}0.118 \\
(0.159)\end{array}$ & $\begin{array}{l}-0.170 \\
(0.140)\end{array}$ & $\begin{array}{c}0.148 \\
(0.164)\end{array}$ \\
\hline educ4_GCSE_5 & $\begin{array}{l}-0.0692 \\
(0.119)\end{array}$ & $\begin{array}{c}0.239 * * \\
(0.114)\end{array}$ & $\begin{array}{l}-0.100 \\
(0.120)\end{array}$ & $\begin{array}{c}0.132 \\
(0.119)\end{array}$ & $\begin{array}{l}-0.124 \\
(0.114)\end{array}$ & $\begin{array}{c}0.142 \\
(0.121)\end{array}$ \\
\hline educ5_A_levels & $\begin{array}{l}-0.0949 \\
(0.116)\end{array}$ & $\begin{array}{c}0.147 \\
(0.109)\end{array}$ & $\begin{array}{l}-0.138 \\
(0.117)\end{array}$ & $\begin{array}{c}0.00920 \\
(0.115)\end{array}$ & $\begin{array}{l}-0.138 \\
(0.112)\end{array}$ & $\begin{array}{l}-0.0472 \\
(0.118)\end{array}$ \\
\hline educ6_high_ed & $\begin{array}{l}-0.136 \\
(0.128)\end{array}$ & $\begin{array}{c}0.173 \\
(0.124)\end{array}$ & $\begin{array}{l}-0.188 \\
(0.130)\end{array}$ & $\begin{array}{l}0.0268 \\
(0.131)\end{array}$ & $\begin{array}{l}-0.157 \\
(0.124)\end{array}$ & $\begin{array}{l}0.0158 \\
(0.132)\end{array}$ \\
\hline educ7_high_ed_degree & $\begin{array}{l}-0.104 \\
(0.118)\end{array}$ & $\begin{array}{l}0.0740 \\
(0.111)\end{array}$ & $\begin{array}{l}-0.139 \\
(0.120)\end{array}$ & $\begin{array}{l}-0.113 \\
(0.116)\end{array}$ & $\begin{array}{l}-0.115 \\
(0.116)\end{array}$ & $\begin{array}{l}-0.141 \\
(0.120)\end{array}$ \\
\hline urban & $\begin{array}{l}-0.0377 \\
(0.0706)\end{array}$ & $\begin{array}{c}0.0901 \\
(0.0804)\end{array}$ & $\begin{array}{l}-0.0504 \\
(0.0725)\end{array}$ & $\begin{array}{c}0.088 \\
(0.0829)\end{array}$ & $\begin{array}{c}-0.028 \\
(0.0689)\end{array}$ & $\begin{array}{c}0.0629 \\
(0.0861)\end{array}$ \\
\hline wealth_mobile & $\begin{array}{c}-0.273 \\
(0.201)\end{array}$ & $\begin{array}{c}0.426^{* * *} \\
(0.109)\end{array}$ & $\begin{array}{c}-0.264 \\
(0.199)\end{array}$ & $\begin{array}{c}0.291 * * \\
(0.116)\end{array}$ & $\begin{array}{l}-0.212 \\
(0.185)\end{array}$ & $\begin{array}{c}0.277 * * \\
(0.114)\end{array}$ \\
\hline wealth_car & $\begin{array}{l}-0.0431 \\
(0.0674)\end{array}$ & $\begin{array}{l}0.178 * * \\
(0.0889)\end{array}$ & $\begin{array}{l}-0.0617 \\
(0.0682)\end{array}$ & $\begin{array}{c}0.0859 \\
(0.0938)\end{array}$ & $\begin{array}{l}-0.0752 \\
(0.0672)\end{array}$ & $\begin{array}{c}0.0497 \\
(0.0967)\end{array}$ \\
\hline wealth_house & $\begin{array}{l}-0.0278 \\
(0.0895)\end{array}$ & $\begin{array}{c}0.0215 \\
(0.0826)\end{array}$ & $\begin{array}{l}0.00487 \\
(0.0932)\end{array}$ & $\begin{array}{l}-0.0312 \\
(0.0859)\end{array}$ & $\begin{array}{c}0.0620 \\
(0.0903)\end{array}$ & $\begin{array}{l}-0.0320 \\
(0.0894)\end{array}$ \\
\hline empl_selfempl & & $\begin{array}{c}-0.410^{* * *} \\
(0.112)\end{array}$ & & $\begin{array}{c}-0.411 * * * \\
(0.114)\end{array}$ & & $\begin{array}{c}-0.462 * * * \\
(0.124)\end{array}$ \\
\hline empl_employed & & $\begin{array}{c}-0.213 * * * \\
(0.0771)\end{array}$ & & $\begin{array}{l}-0.187 * * \\
(0.0791)\end{array}$ & & $\begin{array}{c}-0.226 * * * \\
(0.0848)\end{array}$ \\
\hline living_couple & & 0.0603 & & 0.0527 & & -0.0340 \\
\hline
\end{tabular}




\begin{tabular}{|c|c|c|c|c|c|c|}
\hline & & $(0.0592)$ & & $(0.0614)$ & & $(0.0662)$ \\
\hline \multirow[t]{2}{*}{ nchild_0_4 } & & $-0.216^{*}$ & & $-0.247 * *$ & & $-0.220 *$ \\
\hline & & $(0.111)$ & & (0.109) & & $(0.132)$ \\
\hline \multirow[t]{2}{*}{ nadults_85 } & & $-0.626^{*}$ & & $-0.673 * *$ & & $-0.631 *$ \\
\hline & & $(0.330)$ & & $(0.337)$ & & $(0.349)$ \\
\hline \multirow[t]{2}{*}{ ap_read } & $0.103^{*}$ & $0.162 * *$ & 0.0787 & 0.107 & $0.103^{*}$ & 0.127 \\
\hline & $(0.0578)$ & $(0.0722)$ & $(0.0583)$ & $(0.0746)$ & $(0.0561)$ & $(0.0778)$ \\
\hline \multirow[t]{2}{*}{ ap_write } & -0.139 & $0.351 * *$ & -0.137 & $0.338 * *$ & -0.132 & $0.407 * *$ \\
\hline & $(0.102)$ & $(0.156)$ & (0.103) & $(0.158)$ & $(0.100)$ & $(0.171)$ \\
\hline \multirow[t]{2}{*}{ ap_visual } & $0.118^{*}$ & 0.152 & $0.123^{*}$ & $0.177 *$ & $0.130 * *$ & 0.129 \\
\hline & $(0.0673)$ & $(0.101)$ & $(0.0686)$ & $(0.104)$ & $(0.0662)$ & $(0.108)$ \\
\hline \multirow[t]{2}{*}{ ap_digital } & 0.0675 & $0.261 * * *$ & 0.0613 & $0.207 * *$ & 0.0272 & 0.161 \\
\hline & $(0.0732)$ & $(0.100)$ & $(0.0743)$ & $(0.101)$ & $(0.0718)$ & $(0.108)$ \\
\hline \multirow[t]{2}{*}{ ap_dance } & -0.0915 & 0.162 & -0.113 & 0.162 & -0.0658 & 0.0939 \\
\hline & $(0.0692)$ & (0.107) & $(0.0701)$ & $(0.111)$ & $(0.0688)$ & $(0.116)$ \\
\hline \multirow[t]{2}{*}{ ap_music } & 0.0425 & -0.0592 & 0.0365 & -0.0878 & 0.0479 & -0.0733 \\
\hline & $(0.0745)$ & $(0.0952)$ & $(0.0756)$ & $(0.0963)$ & $(0.0733)$ & $(0.102)$ \\
\hline \multirow[t]{2}{*}{ ap_perform } & 0.116 & 0.167 & 0.141 & 0.161 & 0.0797 & 0.182 \\
\hline & $(0.115)$ & $(0.185)$ & $(0.117)$ & $(0.184)$ & $(0.114)$ & $(0.202)$ \\
\hline \multirow[t]{2}{*}{ ap_collect } & 0.0690 & 0.121 & 0.0551 & 0.120 & 0.0485 & 0.134 \\
\hline & $(0.0687)$ & (0.0889) & $(0.0696)$ & $(0.0913)$ & $(0.0672)$ & $(0.0961)$ \\
\hline \multirow[t]{2}{*}{ pp_cinema } & $0.251 * * *$ & 0.00242 & $0.238 * * *$ & -0.0418 & $0.191 * * *$ & -0.0436 \\
\hline & $(0.0583)$ & $(0.0715)$ & $(0.0595)$ & $(0.0738)$ & $(0.0574)$ & $(0.0760)$ \\
\hline \multirow[t]{2}{*}{ pp_visual } & 0.0304 & 0.0555 & 0.0390 & 0.0247 & -0.00382 & 0.0618 \\
\hline & $(0.0721)$ & $(0.0903)$ & $(0.0735)$ & $(0.0921)$ & $(0.0708)$ & $(0.0977)$ \\
\hline \multirow[t]{2}{*}{ pp_digital } & -0.0433 & 0.0600 & -0.0470 & 0.0684 & -0.204 & 0.181 \\
\hline & $(0.131)$ & $(0.198)$ & (0.133) & $(0.197)$ & $(0.125)$ & $(0.232)$ \\
\hline \multirow[t]{2}{*}{ pp_perf_all } & 0.0136 & -0.0507 & -0.00802 & -0.0503 & -0.000632 & -0.0389 \\
\hline & $(0.0563)$ & $(0.0701)$ & $(0.0574)$ & $(0.0725)$ & $(0.0549)$ & $(0.0747)$ \\
\hline \multirow[t]{2}{*}{ pp_festival } & $-0.127 * *$ & $0.329 * * *$ & $-0.138 * *$ & $0.324 * * *$ & $-0.127 * *$ & $0.400 * * *$ \\
\hline & $(0.0634)$ & $(0.0960)$ & $(0.0646)$ & $(0.0989)$ & $(0.0627)$ & $(0.104)$ \\
\hline \multirow[t]{2}{*}{ pp_exhibit_all } & -0.0989 & -0.124 & $-0.118 *$ & -0.138 & -0.0476 & $-0.170 *$ \\
\hline & $(0.0687)$ & $(0.0816)$ & $(0.0701)$ & $(0.0840)$ & $(0.0679)$ & $(0.0874)$ \\
\hline \multirow[t]{2}{*}{ int_use } & & & $0.443 * * *$ & $0.736 * * *$ & & \\
\hline & & & $(0.0943)$ & $(0.0851)$ & & \\
\hline \multirow[t]{2}{*}{ int_home_comp } & & & & & -0.0208 & $0.719 * * *$ \\
\hline & & & & & $(0.0888)$ & $(0.0887)$ \\
\hline \multirow[t]{2}{*}{ int_games_console } & & & & & $0.731 * * *$ & $1.166^{* * *}$ \\
\hline & & & & & $(0.0738)$ & $(0.255)$ \\
\hline \multirow[t]{2}{*}{ int_mobile } & & & & & $0.136 *$ & $0.424 * * *$ \\
\hline & & & & & $(0.0694)$ & $(0.0814)$ \\
\hline \multirow[t]{2}{*}{ int_psp } & & & & & $0.366 * * *$ & 0.369 \\
\hline & & & & & $(0.119)$ & $(0.314)$ \\
\hline
\end{tabular}




\begin{tabular}{lcccccc} 
Observations & 8,344 & 8,344 & 8,344 & 8,344 & 8,344 & 8,344 \\
Month controls & yes & yes & yes & yes & yes & yes \\
Region controls & yes & yes & yes & yes & yes & yes \\
\hline
\end{tabular}

Standard errors in parentheses. $* * * \mathrm{p}<0.01, * * \mathrm{p}<0.05, * \mathrm{p}<0.1$ 


\section{Figures}

Figure 1. Age of Players today and when growing up

Age of Players
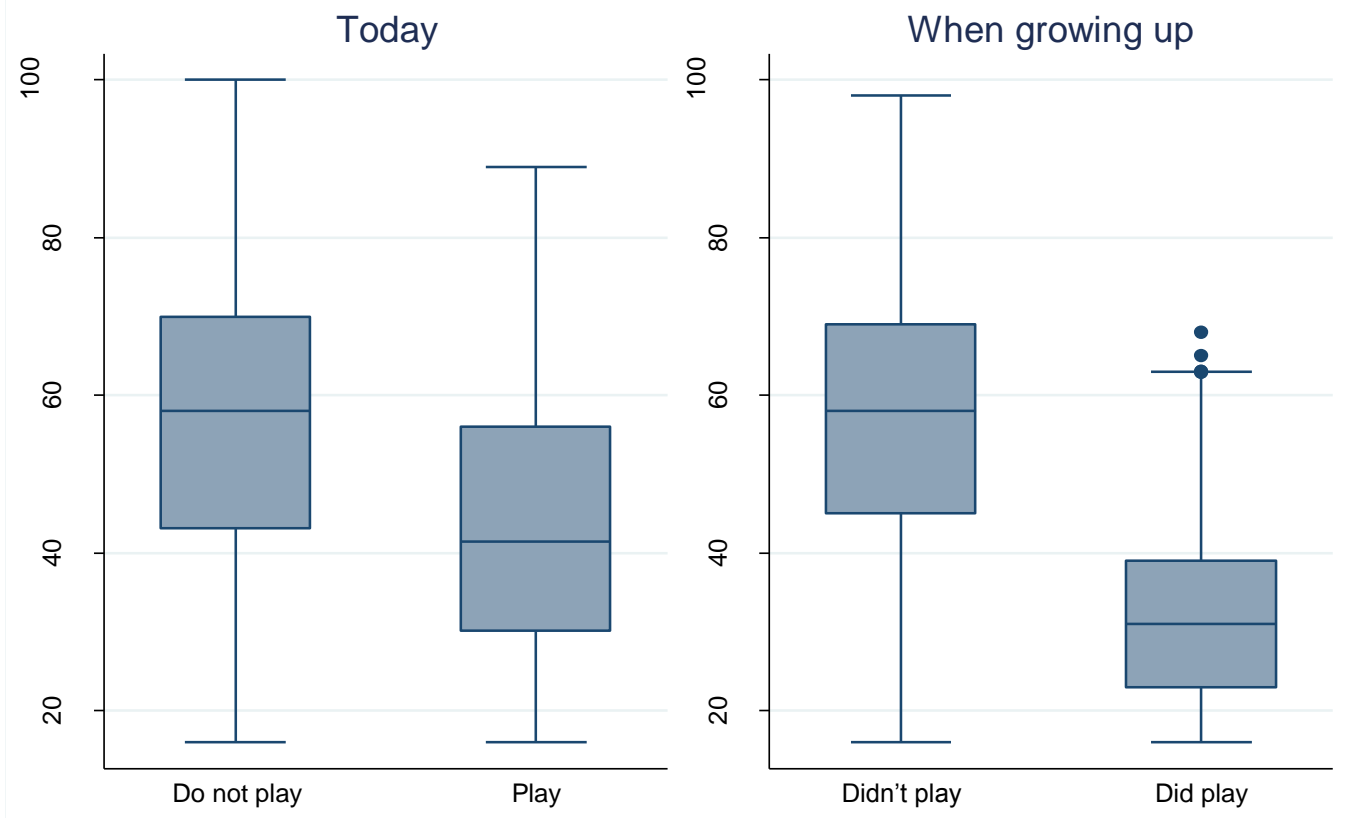

Source: UK Taking Part Adult Survey - 2014/2015 
Figure 2. Frequency of video games playing

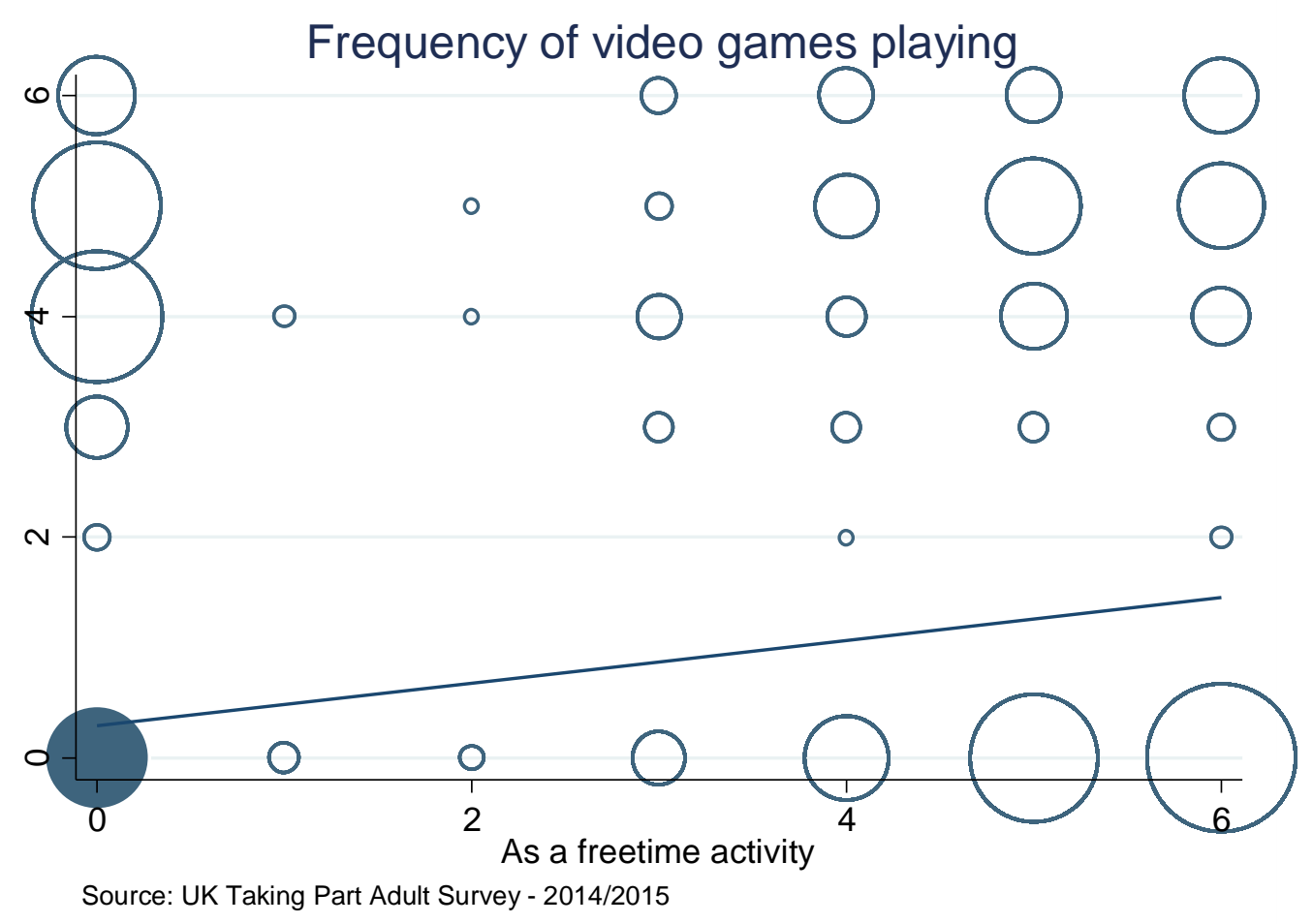




\section{Appendix}

Appendix 1. Video games creators

The Taking Part Survey data for the period we consider contains 107 observations for individuals who had created a video game in the previous 12 months. This small number of observations limits econometric analysis, but it is large enough to derive some indicative insights.

Table A1 presents an extended summary statistics. The first three columns compare the survey responses of those who had created a video game with those who play video games (columns 4-6) and those who do not (columns 7-9). These results show that creators are younger than the average player or non-player, typically male, live in urban areas, have above-average income and have obtained higher levels of educational qualification. A bit more than half of video games creators play video games in their free time, which is more than twice the probability for non-creators. Furthermore, some of the creators may regard playing as part of their work as opposed to a free time activity.

Table A2 provides a detailed overview of cultural activities in which creators and noncreators are involved, along with the resulting difference between the two groups (last column). Interestingly, creators are significantly more likely to be participating in culture and in all but one case the difference is statistically significant at the $99 \%$ confidence interval. 
Table A1. Summary statistics for creators, gamers and non-gamers

\begin{tabular}{|c|c|c|c|c|c|c|c|c|c|}
\hline \multirow[b]{2}{*}{ Variable } & \multicolumn{3}{|c|}{ Creators } & \multicolumn{3}{|c|}{ Gamers } & \multicolumn{3}{|c|}{ Non-gamers } \\
\hline & Obs & Mean & Std. Dev. & Obs & Mean & Std. Dev. & Obs & Mean & Std. Dev \\
\hline vg_play & 107 & 0.56 & 0.50 & 2333 & 1 & 0 & 7484 & 0 & 0 \\
\hline vg_freq & 105 & 2.72 & 2.56 & 2330 & 5.01 & 1.06 & 7484 & 0 & 0 \\
\hline vg_growing & 59 & 0.56 & 0.50 & 1220 & 0.50 & 0.50 & 3607 & 0.13 & 0.34 \\
\hline vg_grow_fr & 9 & 5.00 & 0.71 & 230 & 4.85 & 0.92 & 203 & 4.54 & 0.89 \\
\hline age & 107 & 40.95 & 15.47 & 2330 & 43.20 & 16.96 & 7455 & 56.58 & 17.84 \\
\hline female & 107 & 0.36 & 0.48 & 2333 & 0.51 & 0.50 & 7484 & 0.57 & 0.49 \\
\hline income & 89 & 6.55 & 3.57 & 2038 & 5.36 & 2.95 & 6324 & 5.29 & 2.88 \\
\hline wealth_house & 107 & 0.20 & 0.40 & 2333 & 0.26 & 0.44 & 7484 & 0.43 & 0.50 \\
\hline wealth_car & 107 & 0.79 & 0.41 & 2333 & 0.82 & 0.39 & 7484 & 0.78 & 0.42 \\
\hline educ1_other & 107 & 0.04 & 0.19 & 2333 & 0.02 & 0.16 & 7484 & 0.05 & 0.21 \\
\hline educ2_appr $\sim$ e & 107 & 0.01 & 0.10 & 2333 & 0.03 & 0.16 & 7484 & 0.05 & 0.22 \\
\hline educ3_GCSE 4 & 107 & 0.04 & 0.19 & 2333 & 0.06 & 0.23 & 7484 & 0.05 & 0.22 \\
\hline educ4_GCSE_5 & 107 & 0.16 & 0.37 & 2333 & 0.18 & 0.38 & 7484 & 0.13 & 0.34 \\
\hline educ5_A_le s & 107 & 0.17 & 0.38 & 2333 & 0.21 & 0.41 & 7484 & 0.15 & 0.36 \\
\hline educ6_high d & 107 & 0.12 & 0.33 & 2333 & 0.11 & 0.32 & 7484 & 0.10 & 0.31 \\
\hline educ7_high e & 107 & 0.45 & 0.50 & 2333 & 0.28 & 0.45 & 7484 & 0.25 & 0.43 \\
\hline urban & 107 & 0.85 & 0.36 & 2333 & 0.81 & 0.40 & 7484 & 0.79 & 0.41 \\
\hline
\end{tabular}

Creators are identified as those who respond positively to the question: "In the last 12 months, have you created a video or computer game?" 
Table A2. The differences between creators and non-creators

\begin{tabular}{|c|c|c|c|c|c|c|c|}
\hline & \multicolumn{3}{|c|}{ Creators } & \multicolumn{3}{|c|}{ Non-creators } & \multirow{2}{*}{$\begin{array}{c}\text { Difference } \\
\text { Mean }\end{array}$} \\
\hline & Obs & Mean & Std. Dev. & Obs & Mean & Std. Dev. & \\
\hline ap_dance & 107 & 0.25 & 0.44 & 9817 & 0.13 & 0.33 & $0.13 *$ \\
\hline ap_music & 107 & 0.30 & 0.46 & 9817 & 0.13 & 0.33 & $0.17 *$ \\
\hline ap_perform & 107 & 0.16 & 0.37 & 9817 & 0.03 & 0.18 & $0.13 *$ \\
\hline ap_visual & 107 & 0.25 & 0.44 & 9817 & 0.13 & 0.33 & $0.13^{*}$ \\
\hline ap_digital & 107 & 0.52 & 0.50 & 9817 & 0.12 & 0.33 & $0.40 *$ \\
\hline ap_collect & 107 & 0.33 & 0.47 & 9817 & 0.18 & 0.38 & $0.15^{*}$ \\
\hline ap_read & 107 & 0.77 & 0.43 & 9817 & 0.66 & 0.47 & $0.11^{*}$ \\
\hline ap_write & 107 & 0.25 & 0.44 & 9817 & 0.05 & 0.22 & $0.20 *$ \\
\hline ae_cinema & 107 & 0.73 & 0.45 & 9817 & 0.51 & 0.50 & $0.22 *$ \\
\hline ae_digital & 107 & 0.19 & 0.39 & 9817 & 0.03 & 0.17 & $0.16^{*}$ \\
\hline ae_visual & 107 & 0.37 & 0.49 & 9817 & 0.17 & 0.38 & $0.20 *$ \\
\hline ae_festival & 107 & 0.22 & 0.42 & 9817 & 0.16 & 0.37 & 0.07 \\
\hline ae_perf_all & 107 & 0.77 & 0.43 & 9817 & 0.57 & 0.50 & $0.20 *$ \\
\hline ae_exhibit 1 & 107 & 0.43 & 0.50 & 9817 & 0.25 & 0.43 & $0.18 *$ \\
\hline
\end{tabular}

Note: Difference is calculated as the difference between the mean for creators and mean for noncreators. $*$ denotes difference coefficients that are statistically significant at the $1 \%$ level. 